\title{
EKSPERIMENTASI MODEL PEMBELAJARAN \\ KOOPERATIF TIPE TEAM ASSISTED INDIVIDUALIZATION \\ DENGAN SCAFFOLDING BERBASIS MODUL PADA \\ MATERI GEOMETRIDIMENSI TIGA DITINJAUDARI KEMANDIRIAN BELAJAR SISWA SMK KELAS XI DI KABUPATEN SRAGEN
}

\author{
Hartono $^{1}$, Riyadi $^{2}$, Imam Sujadi ${ }^{3}$ \\ 1,2,3 Prodi Magister Pendidikan Matematika, FKIP Universitas Sebelas Maret Surakarta
}

\begin{abstract}
The purposes of this research were to investigate: (1) which learning models of Team Assisted Individualization learning model with scaffolding based on module (TAI-S), Team Assisted Individualization learning model (TAI), or direct learning model (DL) results in a better learning achievement in the material of three-dimensional geometry; (2) which independence category of student learning, high, medium or low results in a better learning achievement on the material of three-dimensional geometry; (3) in each category of student learning independence, which learning models of the TAI-S, TAI, or DL model results in better learning achievement on the material of three-dimensional geometry. This research used the quasi experimental method with the factorial design of $3 \times 3$. Its population was all the students in Grade XI of Vocational High Schools in Sragen regency. The samples of the research were taken by using the stratified random sampling technique. The data of the research were gathered through documentation, questionnaire, and test. The documentation was employed to investigate the scores of semester test in Mathematics of the students in Semester 1, Academic Year 2012/2013, and was used for balance test among the classes exposed to the TAI-S, TAI, and DL models. The questionnaire was used to find out the independence category of student learning. The test was used to know the students learning achievement in Mathematics with material of three-dimensional geometry. The data of the research were analyzed by using the unbalanced two-way analysis of variance at the significance level of 5\%. The results of the research are as follows: (1) the TAI-S learning model result in a better learning achievement than both the TAI and DL models. There are no any differences in the learning achievement of the students with the TAI learning model and DL model. (2) the students with the high independence category result in better learning achievement than students with medium and low independence category. The students with medium independence category result in better learning achievement than students in low independence category (3) in each category of student learning independence, based on the material of three-dimensional geometry, the TAI-S learning model, TAI learning model and DL model do not have correlation between one and another.
\end{abstract}

Keywords : TAI-S learning model, TAI learning model, DL learning. Three Dimensional Geometry, Learning Independence.

\section{PENDAHULUAN}

Belajar merupakan salah satu aktivitas kehidupan yang penting dan mendasar, sejak manusia lahir sampai mati. Manusia tidak terlepas dari proses belajar sampai kapanpun dan dimanapun. Belajar menjadi salah satu kebutuhan pokok dalam kehidupan. Nilai penting belajar terus meningkat seiring dinamika zaman. Salah satu disiplin pokok ilmu pengetahuan ialah matematika. Matematika berperan strategis dalam proses pendidikan karena ia mendasari banyak disiplin ilmu lain.

Dalam proses pembelajaran di sekolah, matematika sering dianggap sebagai mata pelajaran yang sulit. Banyak siswa merasa terbebani untuk mempelajari matematika. 
Umumnya, mereka beranggapan bahwa matematika ialah disiplin ilmu yang rumit, membingungkan, membosankan, penuh angka dan rumus. Banyak siswa merasa pesimis sebelum mereka benar-benar mulai belajar matematika.

Pada dasarnya mengajar bukan sekadar menyampaikan materi pelajaran tetapi juga melatih kemampuan berpikir siswa. Bagaimana siswa mampu menggunakan struktur kognitifnya secara penuh dan terarah. Materi pelajaran semestinya digunakan sebagai alat untuk melatih kemampuan berpikir, bukan sebagai tujuan. Pengajaran yang terlalu menekankan penyampaian informasi berpotensi menghilangkan konsentrasi dan motivasi belajar siswa (Hamruni, 2012). Proses pembelajaran satu arah melenyapkan keberanian siswa untuk mengemukakan pendapat. Siswa cenderung tidak tahu kesalahan guru. Siswa menjadi lebih individualistis. Siswa tidak peduli dengan sesamanya yang belum memahami materi karena mereka beranggapan bahwa guru bertugas memberikan siswa pemahaman materi belajar.

Paradigma baru pendidikan lebih menekankan pada pengembangan potensi belajar peserta didik. Semua siswa harus aktif dalam pencarian dan pengembangan pengetahuan. Kebenaran ilmu tidak terbatas pada apa yang disampaikan oleh guru. Guru harus menjadi fasilitator yang membimbing siswa agar membentuk pengetahuan secara mandiri. Diharapkan, melalui paradigma baru pendidikan ini, siswa aktif dalam belajar dan berdiskusi di kelas, berani menyampaikan gagasan, menerima ide orang lain dan memiliki kepercayaan diri yang tinggi (Zamroni dalam Sutarno Hadi, 2005).

Hasil pembelajaran merupakan gambaran dari pemahaman siswa terhadap materi pelajaran. Salah satu tolok ukurnya terlihat dalam bentuk nilai mata pelajaran. Sebagai salah satu mata pelajaran pokok yang diajarkan di SMK, matematika sering dipandang siswa sebagai mata pelajaran yang sulit. Ini terlihat dari analisis daya serap hasil Ujian Nasional Mata Pelajaran Matematika untuk Propinsi Jawa Tengah Tahun Pelajaran 2010/2011. Hasil analisis menunjukkan bahwa kemampuan siswa dalam menyelesaikan soal-soal bangun ruang masih tergolong rendah.

Kemampuan siswa dalam menyelesaikan soal perhitungan luas dan volume pada tingkat kabupaten Sragen sebesar 77,81\%, sedangkan kemampuan pada materi yang sama untuk tingkat propinsi Jawa Tengah sebesar 75,04\%. Secara nasional, kemampuan siswa SMK untuk menyelesaikan soal perhitungan luas dan volume bangun ruang sebesar 70,03\%. Data ini menunjukkan bahwa kemampuan siswa dalam menyelesaikan persoalan geometri dimensi tiga masih perlu ditingkatkan. Ini penting mengingat materi pelajaran siswa SMK banyak berhubungan dengan produksi atau praktek kejuruan yang mempelajari benda-benda tiga dimensi secara langsung. Sudah semestinya, matematika bisa menjembatani kebutuhan para siswa akan ilmu pengetahuan, khususnya geometri 
dimensi tiga, sebagai dasar teori sebelum mereka berhadapan langsung dengan bendabenda dimensi tiga pada pelajaran praktik kejuruan.

Keberhasilan belajar siswa dipengaruhi banyak faktor. Sebagian faktor berasal dari diri siswa sendiri, dan sebagian berasal dari guru. Seorang guru harus memiliki kompetensi memadai sebagai pengampu pembelajaran. Guru dengan kompetensi memadai diharapkan akan lebih baik dan mampu menciptakan suasana dan lingkungan belajar yang efektif, sehingga hasil belajar siswa akan optimal. Menurut Ruseffendi (dalam Laila Fitriyana, 2010), sebagian faktor berasal dari siswa. Sejumlah faktor lain berasal dari guru, seperti kemampuan (kompetensi), suasana belajar dan kepribadian guru sebagai model.

Salah satu upaya guru untuk meningkatkan aktivitas dan prestasi belajar siswa ialah pemilihan dan pemakaian model pembelajaran yang relevan. Model pembelajaran yang menempatkan siswa sebagai pusat belajar ialah cooperative learning. Cooperative learning ialah model pembelajaran yang menitikberatkan pada pengelompokkan siswa dengan tingkat kemampuan akademik yang berbeda ke dalam kelompok-kelompok kecil, dan pengelompokan dibuat heterogen. Pembentukan kelompok berdasarkan perbedaan setiap anggota, seperti gender, agama, status sosial-ekonomi, latar belakang etnis dan kemampuan akademik. Kelompok heterogen akan membuka kesempatan untuk saling mengajar (peer tutoring), mendukung dan meningkatkan relasi dan interaksi sesama anggota (Hamruni, 2012). Salah satu model pembelajaran kooperatif adalah Team Assisted Individualization (TAI) yang dikembangkan oleh Slavin. TAI menggabungkan pembelajaran kooperatif dengan pemberian instruksi individual. Dalam TAI, siswa pertama memecahkan masalah secara individual dan kemudian meminta bantuan dari anggota tim mereka. Dengan demikian, mereka dipaksa untuk bekerja dalam sebuah tim untuk meraih satu tujuan, saling dan saling membantu untuk kesuksesan tim mereka (Tarim \& Akdeniz, 2007).

Selain model pembelajaran, kemandirian siswa dalam belajar juga berpengaruh pada prestasi belajar siswa. Perkembangan dalam teknologi pembelajaran menekankan pentingnya kemandirian dalam belajar. Penerapan sistem pembelajaran tuntas, pengajaran perorangan, sistem modul, cara belajar siswa yang aktif dan pendekatan keterampilan proses menekankan kemandirian belajar siswa yang tinggi. Peran siswa ditingkatkan sehingga siswa benar-benar menjadi subyek dalam proses belajar-mengajar. Siswa dipandang sebagai individu yang berusaha meningkatkan kemampuan melalui penguasaan berbagai pengetahuan, keterampilan, nilai-nilai dan sikap.

Kemandirian dalam belajar merupakan prinsip yang penting dalam interaksi belajar-mengajar untuk mencapai tujuan pembelajaran yang telah ditentukan. Jadi, model 
pembelajaran yang memperhatikan kemandirian belajar peserta didik diharapkan dapat meningkatkan kualitas pembelajaran matematika berupa perbaikan prestasi belajar siswa.

Penelitian ini bertujuan untuk mengetahui: (1) manakah model pembelajaran yang menghasilkan prestasi belajar yang lebih baik pada materi geometri dimensi tiga, model pembelajaran kooperatif tipe TAI dengan scaffolding berbasis modul (TAI-S), model pembelajaran kooperatif tipe TAI (TAI) atau model pembelajaran langsung (PL). (2) manakah kategori kemandirian belajar siswa yang menghasilkan prestasi belajar matematika yang lebih baik pada materi geometri dimensi tiga, siswa dengan kemandirian belajar tinggi, sedang atau rendah. (3) pada masing-masing kategori kemandirian belajar siswa, manakah yang menghasilkan prestasi belajar matematika yang lebih baik pada materi geometri dimensi tiga, model pembelajaran koperatif tipe TAI-S, model pembelajaran TAI atau model PL.

\section{METODE PENELITIAN}

Penelitian ini merupakan penelitian eksperimental semu (quasi-experimental research). Variabel bebas dalam penelitian ini adalah model pembelajaran kooperatif tipe TAI dan kemandirian belajar. Sedangkan variabel terikat dalam penelitian ini adalah prestasi belajar matematika. Penelitian ini menggunakan rancangan faktorial $3 \times 3$ untuk mengetahui pengaruh dua variabel bebas terhadap variabel terikat

Populasi pada penelitian ini adalah seluruh siswa kelas XI Sekolah Menengah Kejuruan di Kabupaten Sragen tahun ajaran 2012 / 2013. Teknik pengambilan sampel yang dilakukan adalah dengan mengelompokkan sekolah menjadi 3 kategori (tinggi, sedang dan rendah) berdasarkan rata-rata hasil nilai UN mata pelajaran matematika tahun pelajaran 2010/2011. Secara acak dipilih 1 sekolah dari masing-masing kategori. Kemudian pada tiap sekolah dipilih 2 kelas sebagai kelompok eksperimen dan 1 kelas sebagai kelompok kontrol. Sampel penelitian ini adalah siswa dari SMK Negeri 2 Sragen kelas XI TKR1, XI TITL 1 dan XI TP 1, SMK Negeri 1 Miri kelas XI TKR 1, XI TKR 2 serta XI TKR 3 dan SMK Negeri 1 Kedawung kelas XI TKR 1, XI TKR 2 dan XI TKR 3.

Instrumen yang digunakan dalam penelitian ini adalah tes untuk mengetahui prestasi belajar matematika materi Geometri Dimensi Tiga dan angket untuk mengetahui kemandirian belajar yang dimiliki siswa. Uji keseimbangan terhadap ketiga populasi menggunakan uji anava satu jalan dengan sel tak sama. Hasil Uji keseimbangan diperoleh nilai $\mathrm{F}=1,9128$ dan $\mathrm{F}_{\text {tabel }}=3,00$ dengan daerah kritis $\mathrm{DK}=\{F \mid F>3,00\}$. Karena $\mathrm{F} \notin \mathrm{DK}$, maka $\mathrm{H}_{0}$ diterima. Dapat disimpulkan bahwa ketiga sampel (TAI-S, TAI dan PL) berasal dari populasi yang berkemampuan awal sama atau seimbang. Uji prasyarat dilakukan dengan metode Lilliefors untuk uji normalitas dan 
metode Bartlett untuk uji homogenitas. Hasil uji normalitas pada taraf signifikansi $5 \%$, hipotesis nol, diterima. Hal ini berarti sampel berasal dari populasi yang berdistribusi normal. Hasil uji homogenitas diperoleh nilai $\chi^{2}$ untuk model pembelajaran adalah 1,8627 dan nilai $\chi^{2}$ untuk tingkat kemandirian belajar adalah 1,8804 , daerah penolakan $\mathrm{DK}=\left\{\chi^{2} \mid \chi^{2}>5,991\right\} ; \quad \chi^{2} \notin \mathrm{DK}$ sehingga $\mathrm{H}_{0}$ diterima. Ini berarti populasipopulasi yang dibandingkan memiliki variansi yang sana (homogen). Uji hipotesis yang digunakan adalah anava dua jalan 3x3 dengan sel tak sama.

\section{HASIL PENELITIAN DAN PEMBAHASAN}

Rerata prestasi belajar menurut metode dan kemandirian siswa dapat dilihat pada Tabel 1.

Tabel 1. Rerata Marjinal

\begin{tabular}{ccccc}
\hline \multirow{2}{*}{$\begin{array}{c}\text { Model } \\
\text { Pembelajaran }\end{array}$} & \multicolumn{3}{c}{ Tingkat kemandirian belajar } & Rerata \\
\cline { 2 - 4 } TAI-S & 86,2637 & 76,7308 & 76,9231 & Marjinal \\
\hline T A I & 78,1167 & 75,8120 & 62,2596 & 74,1453 \\
\hline P L & 76,6026 & 73,5577 & 65,5518 & 72,2812 \\
\hline Rerata Marjinal & 79,9376 & 75,3846 & 69,7324 &
\end{tabular}

Hasil Analisis Variansi Dua Jalan Dengan Sel Tak Sama dapat dilihat pada Tabel 2.

Tabel 2. Rangkuman Analisis Variansi Dua Jalan Dengan Sel Tak Sama.

\begin{tabular}{lcccccc}
\hline \multicolumn{1}{c}{ Sumber } & $\mathrm{JK}$ & $\mathrm{dk}$ & $\mathrm{RK}$ & $\mathrm{F}_{\mathrm{obs}}$ & $\mathrm{F}_{\text {tabel }}$ & $\begin{array}{c}\text { Keputusan } \\
\text { Uji }\end{array}$ \\
\hline $\begin{array}{l}\text { Model } \\
\text { Pembelajaran (A) }\end{array}$ & 3427,3853 & 2 & 1713,6926 & 10,8648 & 3,00 & $\mathrm{H}_{0 \mathrm{~A}}$ ditolak \\
\hline $\begin{array}{l}\text { Kemandirian } \\
\text { Belajar (B) }\end{array}$ & 5940,7366 & 2 & 2970,3683 & 18,8322 & 3,00 & $\mathrm{H}_{0 \mathrm{~B}}$ ditolak \\
\hline Interaksi (AB) & 1342,8719 & 4 & 335,7180 & 2,1285 & 2,37 & $\begin{array}{c}\mathrm{H}_{0 \mathrm{AB}} \\
\text { diterima }\end{array}$ \\
\hline Galat & 40851,6537 & 259 & 157,7284 & & & \\
\hline Total & 51562,6474 & 267 & & & & \\
\hline
\end{tabular}

Berdasarkan Tabel 2. di atas dapat dianalisis sebagai berikut:

a. Pada efek utama A (model pembelajaran), diperoleh harga statistik uji $\mathrm{F}=10,8648$ dengan $\mathrm{DK}=\left\{\mathrm{F} \mid \mathrm{F}>3,00=\mathrm{F}_{0,05 ; 2 ; 268}\right\}$, karena $\mathrm{F} \in \mathrm{DK}$ sehingga $\mathrm{H}_{0 \mathrm{~A}}$ ditolak. Hal ini berarti terdapat perbedaan prestasi belajar siswa pada materi Geometri Dimensi Tiga pada penggunaan model pembelajaran kooperatif tipe TAI-S, TAI dan PL. 
b. Pada efek utama B (kemandirian belajar) diperoleh harga statistik uji $F=18,8322$ dengan $D K=\left\{F \mid F>3,00=F_{0,05 ; 2 ; 268}\right\}$, karena $F \in D K$ sehingga $H_{0 B}$ ditolak. Hal ini berarti ada perbedaan prestasi belajar siswa pada materi Geometri Dimensi Tiga pada masing-masing tingkat kemandirian belajar.

c. Pada efek $\mathrm{AB}, \mathrm{H}_{0 \mathrm{AB}}$ diterima karena nilai $\mathrm{F}=2,1285 \notin \mathrm{DK}=\{\mathrm{F} \mid \mathrm{F}>2,37=$ $\left.\mathrm{F}_{0,05 ; 4 ; 268}\right\}$. Hal ini berarti, pada efek interaksi $(\mathrm{AB})$, tidak ada interaksi antara model pembelajaran dan tingkat kemandirian belajar siswa terhadap prestasi belajar matematika.

Hasil uji lanjut pasca Analisis Variansi sebagai berikut :

Tabel 3. Rangkuman Komparasi Ganda Antar Baris

\begin{tabular}{cccc}
\hline $\mathrm{H}_{0}$ & $\mathrm{~F}_{\text {obs }}$ & $2 \mathrm{~F}_{0,05 ; 2 ; 268}$ & Keputusan Uji \\
\hline$\mu_{1 \bullet}=\mu_{2} \bullet$ & 6,7447 & $(2)(3,00)=6,00$ & $\mathrm{H}_{0}$ ditolak \\
\hline$\mu_{1 \bullet}=\mu_{3 \bullet}$ & 12,7073 & $(2)(3,00)=6,00$ & $\mathrm{H}_{0}$ ditolak \\
\hline$\mu_{2 \bullet}=\mu_{3 \bullet}$ & 0,9746 & $(2)(3,00)=6,00$ & $\mathrm{H}_{0}$ diterima \\
\hline
\end{tabular}

Dari Tabel 3 diperoleh kesimpulan sebagai berikut:

a. Dari uji hipotesis $\mathrm{H}_{\mathrm{O}}: \mu_{1}=\mu_{2}$. diperoleh harga statistik uji $\mathrm{F}=6,7447$, dengan $\mathrm{DK}=$ $\left\{\mathrm{F} \mid \mathrm{F}>6,00=2 \mathrm{~F}_{0,05 ; 2 ; 268}\right\}$, karena $\mathrm{F} \in \mathrm{DK}$ maka keputusan ujinya $\mathrm{H}_{\mathrm{O}}$ ditolak. Hal ini berarti ada perbedaan rerata yang signifikan antara prestasi belajar matematika siswa yang dikenai model pembelajaran TAI-S dan model TAI.

b. Dari uji hipotesis $\mathrm{H}_{\mathrm{O}}: \mu_{1}=\mu_{3}$. diperoleh harga statistik uji $\mathrm{F}=12,7073$, dengan DK $=$ $\left\{\mathrm{F} \mid \mathrm{F}>6,00=2 \mathrm{~F}_{0,05 ; 2 ; 268}\right\}$, karena $\mathrm{F} \in \mathrm{DK}$ maka keputusan ujinya $\mathrm{H}_{\mathrm{O}}$ ditolak. Hal ini berarti ada perbedaan rerata yang signifikan antara prestasi belajar matematika siswa dengan model pembelajaran TAI-S dan prestasi belajar matematika siswa dengan model PL.

c. Dari uji hipotesis $\mathrm{H}_{\mathrm{O}}: \mu_{2}=\mu_{3}$. diperoleh harga statistik uji $\mathrm{F}=0,9746$, dengan $\mathrm{DK}=$ $\left\{\mathrm{F} \mid \mathrm{F}>6,00=2 \mathrm{~F}_{0,05 ; 2 ; 268}\right\}$, karena $\mathrm{F} \notin \mathrm{DK}$ maka keputusan ujinya $\mathrm{H}_{\mathrm{O}}$ diterima. Hal ini berarti tidak ada perbedaan rerata yang signifikan antara prestasi belajar matematika siswa dengan model pembelajaran TAI dan model PL.

Sesuai hasil pada poin a di atas diputuskan bahwa $\mathrm{H}_{0}$ ditolak. Hal ini berarti ada perbedaan prestasi belajar siswa dengan model pembelajaran kooperatif tipe TAI-S dan model TAI. Berdasarkan hasil analisis data pada Tabel 1. diperoleh rerata marjinal prestasi belajar siswa yang dikenai model pembelajaran TAI-S adalah 78,9941 dan model TAI adalah 74,1453. Berdasarkan hasil tersebut disimpulkan bahwa prestasi belajar matematika siswa yang dikenai model pembelajaran TAI-S lebih baik daripada TAI.

Menurut pendapat Freire (dalam Kiong, et. al. 2009): “ The teacher is no longer merely the one who teaches, but one who is himself taught inndialogue with the students, who in turn while being taught also teaches. They become jointly 
responsible for a process in which all grow. Students would be actively involved in discussions, clarifying the activity, suggesting ideas, explaining, and justifying their own ideas or providing help to justify or refute others' ideas. Hence, they assumed greater responsibility for their work." Maksudnya, guru bukan lagi sebagai pengajar, tetapi ada dialog dengan para siswa, mereka bersama-sama bertanggung jawab untuk keseluruhan proses. Siswa akan aktif terlibat dalam diskusi, menjelaskan aktivitas, menunjukkan ide-ide, menjelaskan, dan membenarkan ide-ide mereka sendiri atau memberikan bantuan untuk membenarkan atau membantah ide orang lain. Oleh karena itu, para siswa mempunyai tanggung jawab yang lebih besar terhadap pekerjaan mereka.

Dalam pembelajaran TAI-S, siswa dengan kemampuan rendah telah mendapat bantuan berupa modul untuk dipelajari sebelum pembelajaran dimulai. Dengan modul tersebut siswa mempunyai kesempatan untuk mempelajari materi sebelum pembelajaran berlangsung. Guru sebagai fasilitator memberikan bantuan sesuai kebutuhan siswa.

Hal ini sesuai dengan pendapat Kiong \& Yong (2011) bahwa ada lima hal penting perlu diperhatikan untuk suksesnya pembelajaran scaffolding, yaitu : (1) siswa menjelaskan dan membenarkan hasil pekerjaan mereka, (2) guru terus memantau pemahaman siswa, (3) guru mempertimbangkan sudut pandang siswa, (4) Scaffolding / bantuan disesuaikan dengan kebutuhan siswa dan (5) peserta didik belajar dengan memanfaatkan Scaffolding. Guru perlu menempatkan peran mereka sebagai fasilitator dalam proses pengembangan konstruksi pengetahuan matematika dengan menerapkan pembelajaran Scaffolding di kelas.

Hasil uji komparasi ganda untuk model pembelajaran TAI-S dan model PL adalah $F_{1 \cdot-3 \cdot}=12,7073>2 \mathrm{~F}_{\text {tabel }}=6,000$, sehingga $\mathrm{H}_{0}$ ditolak. Hal ini berarti ada perbedaan prestasi belajar siswa dengan model pembelajaran TAI-S dan model PL. Berdasarkan hasil analisis data pada Tabel 1. diperoleh rerata marjinal prestasi belajar siswa yang dikenai model pembelajaran TAI-S diperoleh nilai 78,9941 dan rerata marginal marjinal prestasi belajar siswa yang dikenai model PL 72,2812. Berdasarkan hasil tersebut disimpulkan bahwa prestasi belajar matematika siswa yang dikenai model pembelajaran TAI-S lebih baik daripada prestasi belajar siswa yang dikenai model PL.

Hal ini sesuai pendapat Akinsola dan Olowojaiye (2008) yang menyatakan "Evidence abounds that the conventional teaching method which is the traditional method commonly used in schools, is inadequate for improved students attitude towards Mathematics. This suggested the need to shift from the conventional method of teaching and embrace some other instructional strategies that have been found to have facilitative effect in promoting students' positive attitude towards Mathematics". Artinya sudah banyak bukti bahwa metode pengajaran konvensional yang merupakan metode tradisional biasa digunakan di sekolah-sekolah, tidak cukup untuk meningkatkan sikap siswa terhadap matematika. Hal ini menunjukkan kebutuhan untuk bergeser dari metode pengajaran konvensional dan menerapkan beberapa strategi pembelajaran lainnya yang telah ditemukan memiliki efek fasilitatif dalam meningjatkan sikap positif siswa terhadap matematika. 
Hasil uji komparasi ganda untuk model pembelajaran TAI dengan model PL adalah $F_{2} \cdot-3 \cdot=0,9746<2 \mathrm{~F}_{\text {tabel }}=6,000$, sehingga $\mathrm{H}_{0}$ diterima. Hal ini berarti model pembelajaran TAI sama baiknya dengan PL. Meskipun nilai rerata marginal prestasi belajar siswa yang dikenai model pembelajaran kooperatif tipe TAI dan prestasi belajar siswa yang dikenai model PL berbeda, tetapi perbedaan itu tidak berdampak signifikan terhadap prestasi belajar matematika siswa.

Hasil uji lanjut pasca anava antar sel pada kolom yang sama dapat dilihat pada tabel berikut:

Tabel 4. Rangkuman Komparasi Ganda Antar Kolom

\begin{tabular}{cccc}
\hline $\mathrm{H}_{0}$ & $\mathrm{~F}_{\text {obs }}$ & $2 \mathrm{~F}_{0,05 ; 2 ; 194}$ & Keputusan Uji \\
\hline$\mu_{\bullet 1}=\mu_{\bullet 2}$ & 6,1091 & $(2)(3,00)=6,00$ & $\mathrm{H}_{0}$ ditolak \\
\hline$\mu_{\bullet 1}=\mu_{\bullet 3}$ & 23,5763 & $(2)(3,00)=6,00$ & $\mathrm{H}_{0}$ ditolak \\
\hline$\mu_{\bullet 2}=\mu_{\bullet 3}$ & 9,0049 & $(2)(3,00)=6,00$ & $\mathrm{H}_{0}$ ditolak \\
\hline
\end{tabular}

Dari Tabel 4. diperoleh kesimpulan sebagai berikut:

a. Dari uji hipotesis $\mathrm{H}_{\mathrm{O}}: \mu_{\bullet 1}=\mu_{\bullet 2}$ diperoleh $\mathrm{F}_{\mathrm{obs}}>2 \mathrm{~F}_{0,05 ; 2 ; 268}$, sehingga $\mathrm{H}_{\mathrm{O}}$ ditolak. Hal ini berarti ada perbedaan rerata yang signifikan antara prestasi belajar matematika siswa dengan kemandirian belajar tinggi dan prestasi belajar matematika siswa dengan kemandirian sedang.

b. Dari uji hipotesis $\mathrm{H}_{\mathrm{O}}: \mu_{\bullet 1}=\mu_{\bullet 3}$ diperoleh $\mathrm{F}_{\mathrm{obs}}>2 \mathrm{~F}_{0,05 ; 2 ; 268}$, sehingga $\mathrm{H}_{\mathrm{O}}$ ditolak. Hal ini berarti ada perbedaan rerata yang signifikan antara prestasi belajar matematika siswa dengan kemandirian belajar tinggi dan rendah.

c. Dari uji hipotesis $\mathrm{H}_{\mathrm{O}}: \mu_{\bullet 2}=\mu_{\bullet 3}$ diperoleh $\mathrm{F}_{\mathrm{obs}}>2 \mathrm{~F}_{0,05 ; 2 ; 268}$, sehingga $\mathrm{H}_{\mathrm{O}}$ ditolak. Hal ini berarti ada perbedaan rerata yang signifikan antara prestasi belajar matematika siswa dengan kemandirian belajar sedang dan rendah.

Dari hasil uji lanjut pasca Anava pada poin a di atas disimpulkan bahwa $\mathrm{H}_{0}$ ditolak. Hal ini berarti ada perbedaan prestasi belajar siswa dengan kemandirian belajar tinggi dan kemandirian belajar sedang. Berdasarkan hasil analisis data rerata marginal antara prestasi belajar siswa dengan kemandirian belajar tinggi adalah 79,9376 dan rerata marginal siswa dengan kemandirian sedang adalah 75,3846. Berdasarkan hasil tersebut dapat disimpulkan bahwa prestasi belajar matematika siswa dengan kemandirian belajar tinggi lebih baik daripada prestasi belajar siswa dengan kemandirian belajar sedang.

Hasil uji lanjut pasca anava antara prestasi belajar siswa dengan kemandirian belajar tinggi dan kemandirian rendah diperoleh nilai $F_{\bullet 1-\cdot 3}=23,5763>2 \mathrm{~F}_{\text {tabel }}=$ 6,000 , sehingga $\mathrm{H}_{0}$ ditolak. Hal ini berarti bahwa prestasi belajar siswa dengan kemandirian belajar tinggi lebih baik daripada prestasi belajar siswa dengan kemandirian belajar rendah.

Hasil uji lanjut pasca anava antara kemandirian belajar sedang dengan kemandirian belajar rendah diperoleh nilai $F_{\bullet 2-\bullet}=9,0049>2 \mathrm{~F}_{\text {tabel }}=6,000$, sehingga 
$\mathrm{H}_{0}$ ditolak. Hal ini menyimpulkan bahwa prestasi belajar siswa dengan kemandirian belajar sedang lebih baik daripada prestasi belajar siswa dengan kemandirian belajar rendah. Hal ini dikarenakan siswa dengan tingkat kemandirian belajar tinggi lebih rajin, lebih aktif disaat pembelajaran berlangsung. Selain itu siswa dengan tingkat kemandirian tinggi sering berdiskusi atau bertanya di saat mengalami kesulitan. Mereka juga banyak menggunakan sumber belajar yang lain dan berusaha mencari reverensi sebanyakbanyaknya. Usaha tersebut berdampak positif pada peningkatan pengetahuan terkait materi pelajaran, sehingga memudahkan peningkatan prestasi belajar.

Hal ini sejalan dengan hasil penelitian Kamarski \& Revach (2009), Results indicated that teachers in the Self-Regulated Learning (SRL) program outperformed those in the no-SRL program on various problem solving skills (e.g., reflection and conceptual mathematical explanations) and lesson planning (e.g., task demands and teaching approach). Videotaped observations of actual teaching indicated that the SRL-trained teacher demonstrated more teaching practices that aimed to promote students' understanding and better supported students' regulation of their own learning, compared to the no-SRL-trained teacher. Hasil penelitian menunjukkan bahwa guru dalam Program SRL mengungguli mereka dalam program no-SRL pada berbagai keterampilan pemecahan masalah (misalnya, refleksi dan penjelasan matematika konseptual) dan pelajaran perencanaan (misalnya, tugas tuntutan dan pendekatan pengajaran). Pada pengamatan pengajaran yang sebenarnya menunjukkan bahwa guru SRL terlatih menunjukkan praktek pengajaran yang lebih yang bertujuan untuk meningkatkan pemahaman siswa dan mendukung siswa belajar mandiri.

Pada efek interaksi antara model pembelajaran dan kategori kemandirian disimpulkan bahwa tidak ada interaksi antara model pembelajaran dan kategori kemandirian belajar siswa terhadap prestasi belajar matematika. Dari kenyataan bahwa tidak terdapat interaksi, dapat disimpulkan bahwa karakteristik perbedaan antara siswa dengan model pembelajaran TAI-S, model pembelajaran TAI dan model PL untuk setiap kemandirian belajar tinggi, sedang dan rendah sama. Karakteristik tersebut sama dengan karakteristik marjinal perbedaan model pembelajaran. Secara marjinal pada masingmasing kategori kemandirian belajar, metode pembelajaran TAI-S, menghasilkan prestasi belajar matematika yang lebih baik dibandingkan prestasi belajar dengan model pembelajaran TAI dan model PL. Model pembelajaran TAI menghasilkan prestasi belajar yang lebih baik dibandingkan dengan model PL.

Akhirnya sesuai pendapat Stigler dan Hiebert ( dalam Peterson dan Williams. 2008): "that the primary job of the teacher is to make lessons without intrinsic interest more interesting for their students. The focus may then shift away from mathematics toward showmanship, clever presentation, and in this case, "softening the feel" of the classroom. Maksudnya bahwa tugas utama guru adalah untuk membuat pelajaran tanpa unsur kepentingan pribadi, pelajaran lebih menarik bagi siswa mereka. Fokusnya mungkin kemudian beralih dari pelajaran matematika biasa menjadi ketrampilan dalam pembelajaran, presentasi menarik, dan sesuatu yang, " Membuat nuansa kelas menjadi sejuk (menyenangkan)." 


\section{SIMPULAN DAN SARAN}

Berdasarkan hasil pengujian hipotesis dalam penelitian ini dapat disimpulkan sebagai berikut. (1) Prestasi belajar matematika siswa dengan model pembelajaran kooperatif tipe Team Assisted Individualization dengan scaffolding berbasis Modul lebih baik dibandingkan prestasi belajar matematika siswa dengan model pembelajaran kooperatif tipe TAI dan model pembelajaran langsung. Prestasi belajar matematika siswa dengan model pembelajaran kooperatif tipe TAI scaffolding lebih baik dibandingkan prestasi belajar matematika siswa dengan model pembelajaran langsung. (2) Pada tingkat kemandirian belajar, prestasi belajar matematika siswa dengan tingkat kemandirian belajar tinggi lebih baik dibandingkan prestasi belajar siswa dengan kemandirian belajar sedang dan rendah. Prestasi belajar matematika siswa dengan tingkat kemandirian belajar sedang lebih baik dibandingkan prestasi belajar matematika siswa dengan tingkat kemandirian belajar rendah. (3) Tidak ada interaksi antara penggunaan model pembelajaran dan tingkat kemandirian belajar siswa terhadap prestasi belajar matematika siswa. Ini berarti, kalau dilihat pada masing-masing kemandirian belajar (tinggi, sedang atau rendah), prestasi belajar matematika siswa dengan model pembelajaran kooperatif tipe Team Assisted Individualization dengan scaffolding berbasis Modul juga lebih baik dibandingkan prestasi belajar matematika siswa dengan model pembelajaran kooperatif tipe TAI dan model pembelajaran langsung.

Dari hasil kesimpulan di atas disarankan kepada guru matematika untuk menggunakan model pembelajaran kooperatif tipe TAI dengan scaffolding berbasis modul dan model pembelajaran kooperatif tipe TAI sebagai alternatif pembelajaran untuk meningkatkan prestasi belajar matematika khususnya pada materi Geometri dimensi tiga. Dalam pembelajaran menggunakan kedua model pembelajaran tersebut, guru perlu mempersiapkan perangkat pembelajaran dan ruang belajar yang kondusif agar pembelajaran berjalan efektif dan efisien serta sesuai dengan tujuan pembelajaran.

\section{DAFTAR PUSTAKA}

Akinsola, M. K. \& Olowojaiye, F. B. 2008. "Teacher instructional methods and student attitudes towards mathematics". International Electronic Journal of Mathematics Education. 3 (1) : 60 - 73

Budiyono. 2003. Metodologi Penelitian Pendidikan. Surakarta : UNS Press.

Budiyono. 2009. Statistika Untuk Penelitian. Edisi ke-2.Surakarta : UNS Press.

Hamruni. 2012. Strategi Pembelajaran. Yogyakarta : Insan Madani. 
Kiong, P.L.N. \& Yong, H.T. "Scaffolding as a Teaching Strategy to Enhance Mathematic Learning in the Classrooms". Mara University of Tecnology Sarawak Campus, http://www.ipbl.edu.my/bm/penyelidikan/2001/2001 8 paul.pdf, diakses tanggal 28 September 2012.

Kiong, P.L.N., Singh. P. \& Yong, H.T. 2009. "Constructing mathematics in an interactive classroom context”. Educ Stud Math. 72 (3): 307 - 324

Kramarski, B. \& Revach, T. 2009. "The challenge of self-regulated learning in mathematics teachers' professional training." Educ Stud Math. 72 (3): 379 - 399.

Laila Fitriana. 2010. Pengaruh Model Pembelajaran Cooperative Tipe Group Investigation (GI) dan STAD terhadap Prestasi Belajar Matematika ditinjau dari Kemandirian Belajar siswa. Tesis. Universitas Sebelas Maret

Miftahul Huda. 2011. Cooperative Learning Metode, Teknik, Struktur dan Model Terapan. Yogyakarta: Pustaka Pelajar.

Peterson, B. E. \& Williams, S.R. 2008. "Learning mathematics for teaching in the student teaching experience: two contrasting cases." Journal Mathematics Teacher Education. 11 (6): 459-478

Sutarno Hadi. 2005. Pendidikan Matematika Realistik dan Implementasinya. Banjarmasin : Tulip

Tarim, K \& Akdeniz, F. 2007, "The effects of cooperative learning on Turkish elementarystudents' mathematics achievement and attitudetowards mathematics using TAI and STAD methods". Journal of Educational Studies of Mathematics. $67(1): 77-91$ 